\title{
Evaluation of Erectile Function and Mood Changes among Male Patients with Hansen's disease
}

\section{Original Article}

\author{
Ahmed A. Moussa', Hany H. Dessoki², Ghada A. Ahmed ${ }^{3}$,Mohamed A. Farag ${ }^{4}$ \\ ${ }^{1}$ Department of Andrology, Sexology and S.T.Ds, ${ }^{2}$ Department of psychiatry, ${ }^{3}$ Department of \\ Dermatology and Venereology Faculty of Medicine, Beni-Suef University, Beni-Suef, Egypt \\ ${ }^{4}$ Lecturer of Andrology \& S.T.Ds. Faculty of Medicine Cairo University, Cairo, Egypt ${ }^{4}$
}

\begin{abstract}
Purpose: To evaluate evaluation of the erectile function and mood changes in male patients with Hansen's disease (HD). Methods: this study was conducted on fForty males (40) confirmed patients with Hansen's disease were enrolled in this research., theAll patients were subjected to the underwent the following: full Hhistory taking, International index of erectile function (IIEF-5), Beck anxiety scale and Beck depression scale.

Results: About $77.5 \%$ of our patients had erectile dysfunction, and $87.5 \%$ of patients showed anxiety disorders. while While $52.5 \%$ of patients showed depressive disorders and, $27.5 \%$ of patients had abnormal free testosterone levels. There was A high negative significant correlation revealed between IIEF-5 score and deformity grading, but with there was no significant association between duration or type of leprosy and psychiatric disorders. The results showed significant negative correlation between IIEF-5 and Beck depression inventory. But no statistical significant difference regarding free testosterone level ( $\mathrm{p}$-value=0.109) was found between erectile dysfunction (ED) group and non ED group.

Conclusion: Erectile dysfunction, anxiety and depression are very common in among patients with Hansen's disease. and sSuch problems are related to level of deformity not to type or duration of disease and not related to testosterone level. This finding could be of key importance for the clinical practice because it could modify the current management of patients with Hansen's disease.
\end{abstract}

Key Words: Anxiety, deformity, depression, Hansen's disease, leprosy, IIEF score, sexual dysfunction

Received: 18 August 2016, Accepted: 15 February 2017

Corresponding Author: Mohamed Abdel fatah Farag, Tel.: 00201122702140, Fax:+20226715680, E-mail: fatahelsayed@, hotmail.com

ISSN: 2090-6048, September 2017, Vol. 7, No. 3

\section{INTRODUCTION}

Leprosy, one of the most chronic tropical diseases, is still prevalent in certain parts of the world, particularly India and South America. It acts as a unique psychosocial stressor for the social stigma associated with it. Although it was renamed Hansen's disease, the associated prejudice and social stigma are thought to remain obstacles to its eradication $^{[1]}$.

Many studies revealed that testicular affection with leprosy occurs mainly in the lepromatous type ${ }^{[2]}$. Not all patients complaining of diminished or absent sexual function showed histopathologic evidence of destruction of Leydig cells. This is in agreement with the fact that even castrated adult males do not always lose their potency. But some studies revealed no relationship between impotence and testicular involvement in leprosy ${ }^{[3,4]}$.

Disturbance in sexual potency in these patients may be due to associated psychological problems from of such a disfiguring disease ${ }^{[5]}$. Also, inadequate psychiatric care of people with Hansen's disease, acts as increases the problem. Society maintains negative feelings toward people with Hansen's disease. Problems such as divorce, unemployment and displacement from area of residence are common in affected people ${ }^{[6]}$.Comorbidity among patients with Hansen's disease is particularly common and may have significant implications in terms of choice of treatment.

Several studies have shown increased prevalence of psychological morbidity in patients with leprosy. Chronic neuropathic pain has also been associated with psychological problems and decrease quality of life. In some series, up to $65 \%$ of patients have psychological morbidity, Depression is the most common psychiatric disorder found in these patients.

Early detection and treatment of psychiatric disorders among Hansen's disease patients is a powerful 
psychotherapeutic measure. Integrated healthcare strategy will be beneficial to these patients ${ }^{[7,8]}$.

\section{PATIENTS AND METHODS}

Forty married male patients with Hansen's disease , referred from leprosy clinic in Beni-Suef were enrolled in this research. Inclusion. Criteria of inclusion included Adult adult married males who are diagnosed as cases of Hansen's disease, age between 18 and 60 years old. While the exclusion criteria included unmarried patients, patients below 18 years or above 60 years, other common illness affecting erectile dysfunction as DM, hypertension, etc. Patients who have past history of psychiatric illness, or under treatment for any psychological diseases were also excluded.

All patients signed an informed consent and the research protocol is was approved by local ethical committee.

These patients were subjected to the followings: full-history taking including a) Personal history: age, occupation, years of marriage and numbers of children. b) Medical history: Including co- morbid illness e.g. Diabetes, hypertension, cardiovascular disease, renal disease. c) History of the disease, the duration of the disease. d) Sexual history: sexual activity at last 4 weeks, sexual activity before disease, and frequency of intercourse per month. Thereafter, all patients filled up the following interview validated questionnaires: International Index of Erectile Function-5 (IIEF-5) ${ }^{[22]}$, Beck Anxiety Scale ${ }^{[23]}$ and Beck Depression Scale. Blood free testosterone (FT) levels were measured for all patients.

\section{RESULTS}

A total of 40 patients, age ranged between 2760years (mean 43.4 \pm 9.3). All patients included in this study were married for 0.7- 43 years (mean $17.9 \pm 10.4$ ). The duration of the disease ranged from $0.5-50$ years (mean 12.2 \pm 10.5 ) shown in (Table. 1). 33 Of them, 33 $(82.5 \%)$ were fertile, $7(17.5 \%)$ were infertile, and 18 (45\%) patients had deformities due to Hansen's disease.

International index of erectile function score ranged from 8- 23 (mean 13.4 \pm 5.6)., Nine patients (22.5\%) with no erectile dysfunction versus, $31(77.5 \%)$ were with erectile dysfunction. Of them, two $(5 \%)$ had mild erectile dysfunction, five $(12.5 \%)$ had mild to moderate erectile dysfunction, $24(60 \%)$ moderate erectile dysfunction. Besides, $11(27.5 \%)$ had abnormal free testosterone level, 35 (87.5\%) had anxiety disorders, 21 (52.5\%) had depressive disorders (Table. 2).

There was statistically significant difference between patients with erectile dysfunction and patients without erectile dysfunction regarding Beck anxiety inventory ( $p$-value $<0.05)$. In addition to high statistically significant difference revealed regarding Beck depression inventory ( $p$-value $<0.01)$. But no statistical significant difference regarding free testosterone level ( $p$-value $>$ 0.05 or regarding types of leprosy, $\mathrm{PB} / \mathrm{MB}$ as $P$-value $=0.138$ (Table. 3 ).

There was significant negative correlation between IIEF-5 score and Beck depression inventory ( $P$ value $<$ 0.01 ). But no significant correlation revealed between IIEF-5 score and anxiety disorders, or free testosterone levels (Table. 4).

A high negative significant correlation revealed between IIEF-5 score and deformity grading as $P$ value $=0.002$. However, no significant correlation obtained between deformity grades and anxiety disorders or depressive disorders

There is a high positive significant correlation between anxiety disorders and depressive disorders While no significant correlation observed between free testosterone level and anxiety disorders or depressive disorders.

There was no significant correlation between age of patients and IIEF-5score, free testosterone, anxiety disorders, or depressive disorders

A like, no significant correlation noted between duration of disease and IIEF-5 score, free testosterone level, anxiety disorders, and no significant correlation between duration of disease and depressive disorders. 
Table. 1: Demographic data of the our patients

Range Mean \pm SD

IIEF-5 (International Index of Erectile Function)

$13.4 \pm 5.6$

Free testosterone

$0.62-185$

$70.2 \pm 41.5$

Beck anxiety inventory

$13.7 \pm 5.1$

Beck depression inventory

Age

27-60

$43 \pm 9.3$

Duration of marriage

0.7-43

$17.9 \pm 10.4$

Duration of disease

0.5-50

$12.2 \pm 10.5$

Table. 2: Erectile function, Beck anxiety inventory, Beck depression inventory and free testosterone in our patients

\begin{tabular}{|c|c|c|c|}
\hline Mood changes & & Frequency & $\%$ \\
\hline \multirow{5}{*}{ IIEF5 } & No erectile dysfunction & 9 & 22.5 \\
\hline & Mild erectile dysfunction & 2 & 5 \\
\hline & & & \\
\hline & $\begin{array}{l}\text { Mild to moderate } \\
\text { erectile dysfunction }\end{array}$ & 5 & 12.5 \\
\hline & Moderate erectile dysfunction & 24 & 60 \\
\hline \multirow{5}{*}{ Beck anxiety inventory } & No or Minimal anxiety & 5 & 12.5 \\
\hline & Mild anxiety & 20 & 50 \\
\hline & & & \\
\hline & Moderate anxiety & 13 & 32.5 \\
\hline & Severe anxiety & 2 & 5 \\
\hline \multirow{3}{*}{ Beck depression inventory } & No or minimal depression & 19 & 47.5 \\
\hline & Mild depression & 17 & 42.5 \\
\hline & Moderate depression & 4 & 10 \\
\hline \multirow{3}{*}{ Free testosterone } & Normal & 29 & 72.5 \\
\hline & & & \\
\hline & Abnormal & 11 & 27.5 \\
\hline
\end{tabular}


Table. 3: Comparison between patients without erectile dysfunction and patients with erectile dysfunction

\begin{tabular}{|c|c|c|c|c|}
\hline Parameters & $\begin{array}{l}\text { No erectile dysfunction } \\
\qquad(\mathrm{n}=9)\end{array}$ & $\begin{array}{l}\text { Erectile dysfunction } \\
\qquad(\mathrm{n}=31)\end{array}$ & $P$ value & \\
\hline Beck anxiety inventory & $5-16$ & $7-27$ & & \\
\hline Range & $10 \pm 4.15$ & $14.58 \pm 4.9$ & $0.014 *$ & \\
\hline \multicolumn{5}{|l|}{$\mathrm{Mean} \pm \mathrm{SD}$} \\
\hline depression & & & & \\
\hline inventory & $5-16$ & $7-21$ & $0.008 * *$ & \\
\hline Range & $9.33 \pm 4$ & $13.9 \pm 4.42$ & & \\
\hline \multicolumn{5}{|l|}{$\operatorname{Mean} \pm \mathrm{SD}$} \\
\hline \multirow{5}{*}{ Sexual history } & Ejaculation & $7(77.8 \%)$ & $26(83.9 \%)$ & 0.504 \\
\hline & Libido & $4(44.4 \%)$ & $21(67.7 \%)$ & 0.189 \\
\hline & Manual Stimulation & $0(0 \%)$ & $11(35.5 \%)$ & $0.037 *$ \\
\hline & Morning Erection & $0(0 \%)$ & $15(48.4 \%)$ & $0.007 * *$ \\
\hline & Fertility & $1(11.1 \%)$ & $6(19.4 \%)$ & 0.496 \\
\hline Types of leprosy, PB/MB & $4(44.4 \%) / 5(55.9 \%)$ & $6(19.4 \%) / 25(80.6 \%)$ & 0.138 & 0.138 \\
\hline
\end{tabular}

Table. 4: Correlation between IIEF-5 score and some parameters (Free testosterone, beck anxiety inventory and Beck depression inventory)

\begin{tabular}{lccc}
\hline & $\mathrm{r}$ & P value & Sig. \\
\hline Free testosterone & 0.3 & 0.109 & NS \\
Beck anxiety inventory & -0.1 & 0.726 & NS \\
Beck depression inventory & -0.5 & 0.002 & HS \\
\hline
\end{tabular}

\section{DISCUSSION}

The present study included 40 patients; of them 31 suffered from Ed ED while 9 patients showed normal erectile function. Since testicular affection is common in leprotic patients due to affection of Leydig cells, we compared the Ed ED patients with non Ed ED patients as regards the testosterone levels. but However, there was no significant statistical difference between ED and non-ED patients.

Also, there was no significant statistical correlation between IIEF-5 and free testosterone $(P$ value $=0.19)$ in both groups.

The relation between testosterone level and sexual function is controversial. Buena et $a l^{[8]}$, examined the relationship between serum $\mathrm{T}$ levels and sexual function when $\mathrm{T}$ levels are varied in the normal male range by pharmacological means. Two groups of healthy men were treated with a depot form of GnRH agonist to suppress endogenous $\mathrm{T}$ production and were given either $4(n=6)$ or $8(n=5) \mathrm{mg} / \mathrm{d}$ T replacement by a sustained release, long-acting $\mathrm{T}$ microcapsule formulation. Duration of tumescence, libido and sexual activity were not significantly different between the 4 and $8 \mathrm{mg}$ groups. These results indicate that erectile function and sexual activity and feelings are restored by relatively low $\mathrm{T}$ levels. This may help explain why some partially hypogonadal men continue to have normal sexual function.

But Aversa et a ${ }^{[9]}$ mentioned that in all ED patients there was a strong direct correlation between resistive index values and FT levels $(\mathrm{r}=0.47, P=0.002)$; the relationship was maintained also when adjusted for age, SHBG and estradiol $(\mathrm{r}=0.37, P=0.02)$. These results indicate that in men with erectile dysfunction low free testosterone may correlate independently of age with the impaired relaxation of cavernous smooth muscles. These findings give clinical support to the experimental knowledge of the importance of androgens in regulating smooth muscle function in the penis.

Also Nigam, et al ${ }^{[21]}$ reported noted that not all cases 
of leprosy patients who complained of diminished or absent sexual function showed histopathologic evidence of destruction of Leydig cells. and Subsequnetly, they believed that this disturbance in sexual potency in these patients is partially due to an associated psychological state produced in the patients by such a disfiguring disease. Sugimori, et $a l^{[11]}$. reported ED associated significantly with depression and anxiety status only in late 40 s to early 50 s (45-55 years) in male Japanese.

In present the current study, there was high negative significant correlation between IIEF-5 and Beck depression inventory attributed, this may be due to the strong association between depression and erectile dysfunction., whichThis was in agreement with the previously obtained results suggested by Alfredo Nicolosi et $a l^{[10]}$ and Sugimori, et $a l^{[11]}$.

In the present the study; generalized anxiety disorder was the most commonest psychiatric disorder $(87.5 \%)$ followed by depressive disorders (52.5\%). which This was in agreement with the study by Bhatia, et al. ${ }^{[12]}$. Against what had beenand inconsistent with reported in some other previous studies ${ }^{[13-15]}$ that reported reporting depression was the most common psychiatric diagnosis followed by anxiety.

In this study, there was no significant correlation between duration of disease and anxiety or depressive disorders which is in agreement with Behere 1981 and Bharath et al. 1997 the result suggested by ${ }^{[16,17]}$.

Among our patients, no significant correlation revealed between free testosterone level and depressive disorders, unlike the reported by Shores, et al. ${ }^{[18]}$ and we have no explanation for such results.

In present study, no significant correlation was found between physical deformity and anxiety disorders. Also, no significant correlation was found between physical deformity and depression in agreement with the study by Bhatia, et al. ${ }^{[12]}$ but against what had been reported in some previous studies ${ }^{[19,20]}$.

In this work, a highly negative significant correlation revealed between deformity grade and erectile function as $P$ value $=0.002$ and a high positive significant correlation between anxiety disorders and depressive disorders.

Erectile dysfunction is one of the complications of leprosy that may be due to testicular affection or the associated psychological disorders. Such a disfiguring disease and these psychiatric disorders largely go unrecognized by health-care professionals and service providers of these patients. So, there is a growing need to treat these psychiatric and sexual disorders.
Psychiatric care should be practiced as a part of comprehensive health care of patients with leprosy.

\section{CONCLUSION}

Erectile dysfunction, anxiety and depression are very common in Hansen's disease. and sSuch problems are related to level of deformity and non-related not to type or duration of the disease, and not related nor to testosterone level. This finding could be of key importance for the clinical practice because it could modify the current management of patient withfor Hansen's disease.

\section{CONFLICT OF INTEREST}

There are no conflicts of interest.

\section{REFERENCES}

1. Briden A, Maguire E. An assessment of knowledge and attitudes towards leprosy/ Hansen's disease amongst healthcare workers in Guyana. Lepr Rev. 2003; 74: 154-62.

2. Nigam P, Mukhija RD, Gupta AK, Dayal SG, Goyal BM. Gonadal involvement in leprosy, study of gynaecomastia, testicular and epididymal involvement and therapeutic efficacy of indigenous drugs. Hansenol Int $1984 ; 9: 10-20$

3. Grabstald, H. \& Swan, L.L. Genito-urinary lesions in leprosy with special reference to the problem of atrophy of the tests. J. Amer. Med. Ass., (1952): 149 (14): 12871291-

4. El-Shiemy, S.; El-Hefnawl, H.: Abdel-fattah, A.; El-okbi. M; Farid, A. Testicular and epididymal involvement in leprosy patients, with special reference to Gynaecomastia. Int. J. Derm., (1976): 15(1): 52- 58.

5. Kaur H, Ramesh V. Social problems of women leprosy patients: A study conducted at 2 urban leprosy centers in Delhi. Lepr Rev. 1994; 65: 361-75

6. Tsutsumi A, Izutsu T, Akramul Islam MD, Amed JU, Nakahara S, et al. (2004) Depressive status of leprosy patients in Bangladesh: association with selfperception of stigma. Lepr Rev 75: 57-66.

7. Senturk V, Stewart R, Sagduyu A (2007) Screening for mental disorders in leprosy patients: comparing the internal consistency and screening properties of HADS and GHQ-12. Lepr Rev 78: 231-242.

8. Buena F, Swerdloff RS, Steiner BS, Lutchmansingh P, Peterson MA, Pandian MR, Galmarini M, Bhasin S. Sexual function does not change when serum 
testosterone levels are pharmacologically varied within the normal male range, Fertility and Sterility,1993, 59(5):1118- 1123 .

9. Aversa. A, Isidori. A. M, Martino. M. U., Caprio M, Fabbrini E, Rocchietti-March M, Frajese G, Fabbri A. Androgens and penile erection: evidence for a direct relationship between free testosterone and cavernous vasodilation in men with erectile dysfunction. Clinical Endocrinology, Volume 53, Issue 4 October 2000 Pages 517-522.

10. Alfredo Nicolosi, Edson D. Moreira Jr, Marco Villa, Dale B. Glasser. A population study of the association between sexual function, sexual satisfaction and depressive symptoms in men. Journal of Affective Disorders, 15 October 2004, Vol.82 (2):235-243.

11. Sugimori, H., Yoshida, K., Tanaka, T., Baba, K., Nishida, T., Nakazawa, R. and Iwamoto, T. (2005), ORIGINAL RESEARCH-PSYCHOLOGY: Relationships between Erectile Dysfunction, Depression, and Anxiety in Japanese Subjects. Journal of Sexual Medicine, 2: 390-396.

12. Bhatia MS, Chandra R, Bhattacharya SN, Imran M. Psychiatric morbidity and pattern of dysfunction in patients with leprosy. Indian J Dermatol. 2006; $51: 23-5$.

13. Verma KK, Gautam S. Psychiatric morbidity in displaced leprosy patients. Indian J Leprosy.1994; 66:339-43.

14. Anita Nagargoje, G. R. Mundhada, S. B. Deshmukh, A. V. Saboo. "Psychiatric Co-Morbidity in Persons with Hansen's Disease". Journal of Evidence based Medicine and Healthcare; Volume 2, Issue 19, May 11, 2015; Page: 2872 -2881.

15. Kumar JH, Verghese A. Psychiatric disturbance among leprosy patients. An epidemiological study. Int J Lepr Other Mycobact Dis, 1980; 48: 431-434.
16. Behere PB. Psychological reactions to leprosy. Lepr India, 1981; 53: $266-72$.

17. Bharath S, Shamsundar C, Raghuram R, Subbakrishna DK. Psychiatric morbidity in leprosy and psoriasis-a comparative study.Indian J Lepr, 1997; 69: 341- 6.

18. Shores MM, Moceri VM, Sloan KL, Matsumoto AM, Kivlahan DR Low testosterone levels predict incident depressive illness in older men: effects of age and medical morbidity, The Journal of Clinical Psychiatry [2005, 66(1):7- 14].

19. Ramanathan U, Srivastav I, Ramu G. Psychiatric morbidity in patients with leprosy. XII International Leprosy Proceedings, New Delhi, 1984, 810- 1.

20. Philip R. Study of psycho-social aspect of deformed and non-deformed Hansen's patients: A cross sectional comparative study at Philadelphia Leprosy Hospital, Salur, South India. Abstract of Congress Papers. 1998; 66:4,135A.

21. Nigam P, Mukhija RD, Gupta AK, Dayal SG, Goyal BM. Gonadal involvement in leprosy, study of gynaecomastia, testicular and epididymal involvement and therapeutic efficacy of indigenous drugs. Hansenol Int 1984; 9:10 -20.

22. Mohamad Arafa, Rany Shamloul. The arabic version of the Erection Hardness Score. Journal of sexual medicine, December 2009Volume 6, Issue 12, Pages 3501-3503.

23. Leyfer, OT; Ruberg, JL; Woodruff-Borden, J. "Examination of the utility of the Beck Anxiety Inventory and its factors as a screener for anxiety disorders." Journal of anxiety disorders. (2006) 20 (4): 444-58. 